SSCL-SR-1233

\title{
SSCL Groundwater Model
}

V. Romero, J. Bull, G. Stapleton,

S. Baker, D. Goss, and L. Coulson

\section{Superconducting Super Collider Laboratory* 2550 Beckleymeade Ave. \\ Dallas, TX 75237 USA}

February 1994

*Operated by the Universities Research Association, Inc., for the U.S. Department of Energy under Contract No. DE-AC35-89ER40486. 


\subsection{BACKGROUND}

Activation of groundwater due to accelerator operations has been a consideration since the conceptual stages of the SSC. Prior to site selection, an elementary hydrological model assuming a porous medium with a shallow well in proximity to the tunnel was used to determine the radionuclide concentrations in the water pumped from a well. ${ }^{1}$ The model assumed that radionuclides produced within a few feet of the tunnel would migrate to the shallow well and be diluted as the well drew water from a conically symmetric region. This model was used as an order of magnitude estimate to verify that the SSC could operate within regulatory requirements.

After the Ellis County site was selected, the compatibility of this model with the site specific geology was evaluated. The host geology at the selected site is low permeability rock, Austin chalk, shale, and marl, however, vertical fractures do exist. It is known that, at least near the surface, water moves through some of these fracture zones both horizontally and to a limited extent, vertically. Since the host rock has a low permeability, groundwater in proximity to the tunnel would have to travel primarily through fractures. ${ }^{2}$ This hydrology is not compatible with the above mentioned model since water does not percolate uniformly from the surrounding rock into local wells. The amount of dilution of activated water will vary significantly depending on the specific relationship of the well to the activation zone. A further complication in the original model is that it assumes the high energy particles escaping from the accelerator enclosure are localized. The model does not provide for particles being lost over a large area as will happen with routine operational losses. These losses will be distributed along the accelerator over the life of the project. The SSCL groundwater model has been recast to account for the site specific hydrology and both point and distributed losses. Using the new groundwater model, the SSC accelerators are designed to limit the activation concentration in the water located one meter outside the accelerator enclosure to meet the federal drinking water standards. This technical note provides the uetails of this model.

\subsection{CONCENTRATION LIMITS}

The National Primary Drinking Water Regulations (40 CFR 141) specifies the annual effective dose equivalent received by an individual, from drinking water taken from a public drinking water supply, is not to exceed $4 \mathrm{mrem} / \mathrm{yr}$. The isotopic concentration limits for drinking water are based on ani individual ingesting two liters of water per day - every day for a year. For the long lived accelerator produced radionuclides found leachable from Ellis County rock ${ }^{3}$ the drinking water concentration limits are $20 \mathrm{pCi} / \mathrm{ml}$ for ${ }^{3} \mathrm{H}$ and $0.4 \mathrm{pCi} / \mathrm{ml}$ for ${ }^{22} \mathrm{Na}$. The $20 \mathrm{pCi} / \mathrm{ml}$ limit for ${ }^{3} \mathrm{H}$ is specifically stipulated in the regulations and is more restrictive for ${ }^{3} \mathrm{H}$ than the $4 \mathrm{mrem} / \mathrm{yr}$ requirement which makes this limit the most restrictive in the SSCL groundwater model.

The limits for release to surface waters are defined by the Derived Concentration Guides (DCG) contained in DOE Order 5400.5. The DCG values are provided as reference values for conducting radiological environmental protection programs at operational DOE facilities. The Order stipulates that surface water can be released without treatment if it is below the DCG level, and a discharge to sanitary sewage can occur without treatment if it is below five times the DCG level. The DCG levels are $2000 \mathrm{pCi} / \mathrm{ml}$ for ${ }^{3} \mathrm{H}$ and $10 \mathrm{pCi} / \mathrm{ml}$ for ${ }^{22} \mathrm{Na}$ which corresponds to $100 \mathrm{mrem} / \mathrm{yr}$ if ingested. The State of Texas limits are $3000 \mathrm{pCi} / \mathrm{ml}$ for ${ }^{3} \mathrm{H}$ and $40 \mathrm{pCi} / \mathrm{ml}$ for ${ }^{22} \mathrm{Na}$ from Appendix $21-\mathrm{A}$, Table II of the Texas Regulations for the Control of Raciation, Part 21.

\subsection{GROUNDWATER MODEL}

\subsection{Activation Zone}

The groundwater model is based on the concept of an "activation zone," which is the area surrounding the region of interest that contains nearly all of the activation. Analysis show that over $99.9 \%$ of the total activity is contained in a 4-meter region surrounding the tunnel. By calculating the radioactivity distribution radially 
outward from the enclosure perpendicular to the direction of the beam, it can be shown that the concentration at one meter represents the average concentration in the 4-meter region. The scheme to meet the National Primary Drinking Water Regulations is then reduced to meeting the concentration requirements at the one meter location.

As a high energy particle escapes the accelerator enclosure and enters the surrounding ground (rock and soil) it begins a series of nuclear interactions, referred to as stars, which result in a cascade of hadrons. The star density has been calculated in the Ellis county ground surrounding the accelerator runnels by various Monte-Carlo cascade codes. ${ }^{1,4}$ These calculations show, to a good approximation, that the star density decreases exponentially radially out from the tunnel and is reduced by a factor of 10 for every meter of ground as shown in Figure 1. The concept of a 4-meter "activation zone" can be validated from Figure 1 by noting that the star density is essentially zero and the percent of all stars is asymptotic at the 4-meter location. From these calculations the linear absorption coefficient $(\mu)$ for Ellis county ground can be approximated by (there is some variation in the absorption coefficient with radial location, but the following assumes a conservative constant fall-off):

$$
\begin{gathered}
\frac{1}{10}=e^{-\mu} \\
\mu=2.30\left(m^{-1}\right) .
\end{gathered}
$$

The integrated star density in the ground surrounding the tunnel is proportional to (using cylindricai coordinates)

$$
A_{s} \propto \iint_{Z} \int_{\theta} \frac{1}{2 \pi r} e^{-\mu r} d z r d r d \theta .
$$

If we now consider the integrated star density per unit length along the tunnel the total number of stars per unit length becomes

$$
A_{s} \propto \int_{r=a}^{\infty} \int_{\theta=0}^{2 \pi} \frac{1}{2 \pi r} e^{-\mu r} r d r d \theta=\frac{e^{-\mu a}}{\mu}
$$

where $a$ is the tunnel radius. If the "activation zone" is considered to extend 4 meters radially the total star density in this zone is proportional to

$$
A_{s} \propto \int_{r=a}^{a+4} \int_{\theta=0}^{2 \pi} \frac{1}{2 \pi r} e^{-\mu r} r d r d \theta=\frac{e^{-\mu a}}{\mu}[1-0.0001],
$$

which shows that the number of stars per unit length in the "activation zone" corresponds to $99.99 \%$ of all the stars per unit length at a particular $z$ location (along the beam axis). This result assumes symmetry in the $\theta$ dimension. If the loss point is not in the center of the enclosure, the maximum concentration in the ground could be much higher than the average concentration at some radial distance from the loss point or from the center of the enclosure. Thus, care needs to be taken in developing the geometry for the Monte-Carlo calculation to ensure that the predictions are consistent with the ground water model assumptions. (It should be noted that this result is independent of coordinate system and number of dimensions, i.e., 1, 2, or 3.) 
The average stint Jensity in the "activation zone" is given by dividing the total number of stars by the volume of the activation zone. As can be seen graphicaily in Figure 2, the local value of the star density 1 meter into the ground is a good approximation (slightly conservative) of the average star density in the activation zone.

In summary the "activation zone" is considered to extend 4 meters radially from the tunnel enclosure and accounts for virtually all of the activation products. Further, the activation concentration located one meter outside the accelerator enclosure represents the average activation concentration in the "activation zone." Therefore, meeting the prescribed limits at the 1-meter location ensures compliance over the "activation zone" since it represents the integrated activity. Note that the average is determined in the direction perpendicular to the beam and not along the beam axis.

This model has an advantage over well models in that it does not rely on transport or dilution to meet concentration limits. Further it can be applied at loss points as well as everywhere along the accelerator to account for both point and distributed losses. The one meter distance provides a reasonable clearance from any disturbance zone produced by tunnel construction activity. And it also permits credit to be taken for water movement towards and into the tunnel since the peak concentration immediately adjacent to the tunnel is allowed to be higher (by a factor of 10 ) than the average concentration.

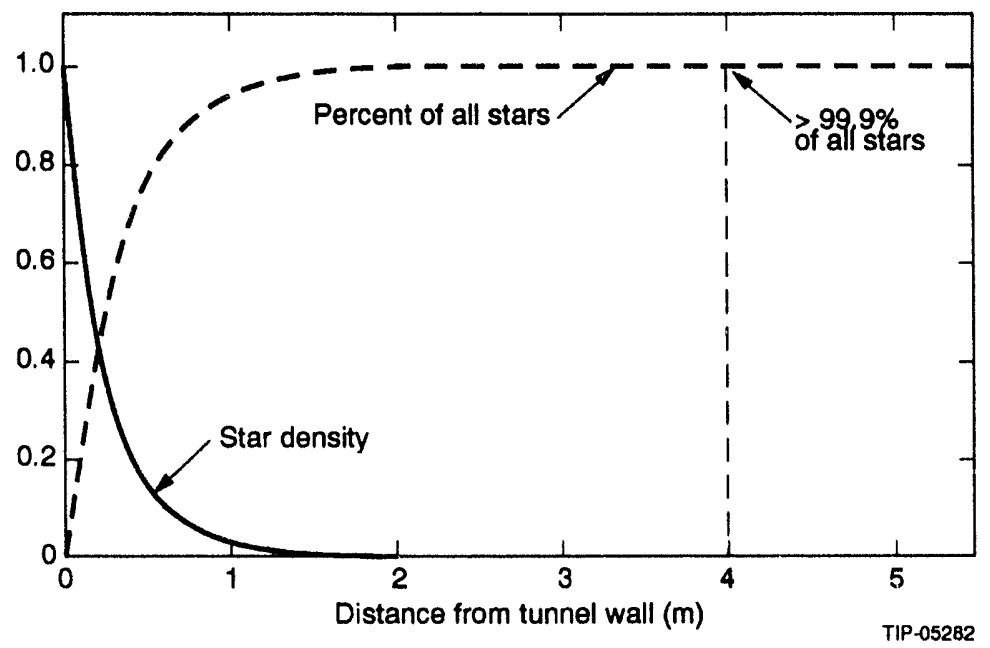

Figure 1. Groundwater activation model.

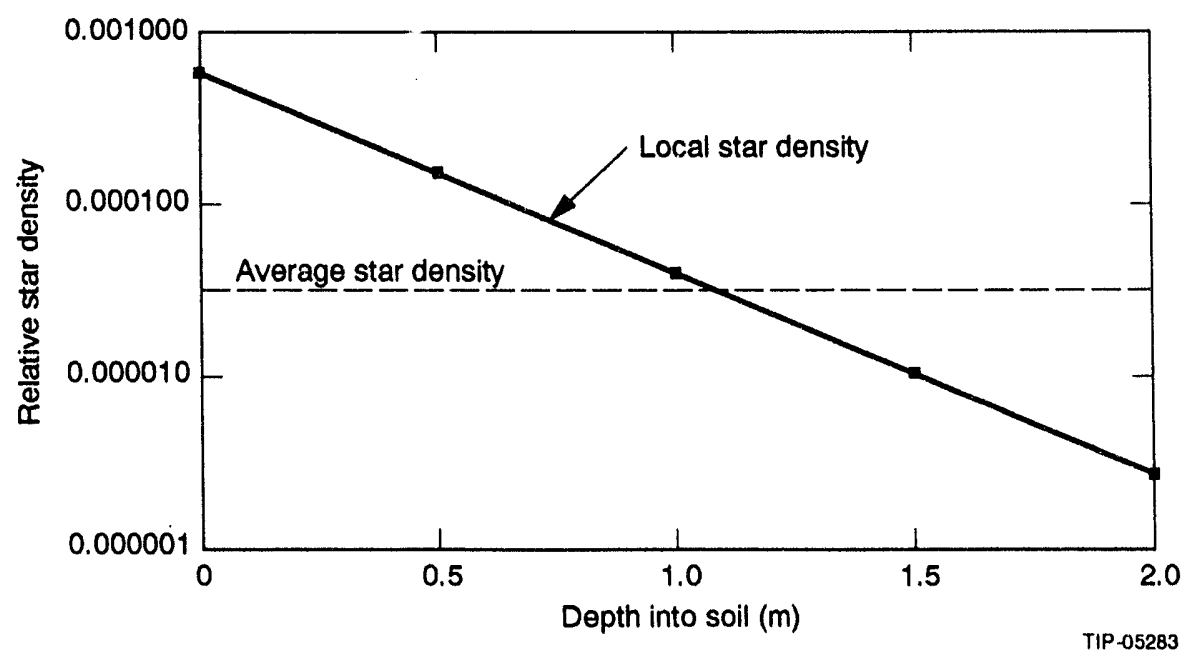

Figure 2. Local star density vs. average in activation zone. 


\subsection{Activation Concentrations}

The total number of atoms per cubic centimeter of a particular radionuclide produced in ground per incident proton, $n_{i}$, can be written as

$$
n_{i}=S K_{i}
$$

where $S$ is the star density (in stars $/ \mathrm{cm}^{3}$ ) per proton and $K_{i}$, the production factor, is the probability that an atom of radionuclide $i$ will be produced for each star. The production factor, the ratio of the cross section for production of isotope $i$ to the total nuclear interaction cross section, is dependent on the earth or rock composition. Various rock samples collected from the SSC site have been irradiated to determine the production factors for ${ }^{3} \mathrm{H}$ and ${ }^{22} \mathrm{Na}$ (Reference 5). Table 1 summarizes the production factors for $\mathrm{SSC}$ rocks.

Table 1. Production Factors for SSC Rocks.

\begin{tabular}{|l|c|c|}
\hline \multicolumn{1}{|c|}{ Materlal } & \multicolumn{2}{|c|}{$\begin{array}{c}\text { Production Factor, } \boldsymbol{K}_{\text {I }} \\
\text { (atoms/star) }\end{array}$} \\
\hline & $3 \mathrm{H}$ & $22 \mathrm{Na}$ \\
\hline Austln Chalk & 0.02 & 0.01 \\
\hline Eagle Ford Shale & 0.03 & 0.04 \\
\hline Taylor Marl & 0.03 & 0.04 \\
\hline Compacted flll (chalk) & 0.02 & 0.01 \\
\hline
\end{tabular}

If the beam losses have been uniform over many years, the activation rate will have reached equilibrium (saturation) for both nuclides. The specific activity of isotope $i$ in $\mathrm{pCi} / \mathrm{g}$ can then be expressed as

$$
a_{i}=\frac{\dot{N}_{p} S K_{i}}{\varrho_{r} \times 0.037 \quad \mathrm{~B}_{\mathrm{q}} / \mathrm{pC}_{\mathrm{i}}}
$$

where $\dot{N}_{p}$ is the number of protons lost per second, and $\varrho_{r}$ is the wet density of the rock, in $\mathrm{g} / \mathrm{cm}^{3}$.

Not all of the activity produced in the rock is picked up and transported by the groundwater. A large portion of it remains trapped in the rock. The fraction of activity picked up by the groundwater depends mainly on the chemical and physical properties of the rock exposed to the water. These leachable fractions for Ellis County soil and rock have been determined experimentally. ${ }^{6}$ Leaching of radionuclides is done by a method which simulates percolation of water through the sample. ${ }^{*}$ It is this leachable concentration at saturation which must be met at the one meter location.

\footnotetext{
* Determining the concentration of ${ }^{3} \mathrm{H}$ in a rock sample by distillation of the sample will result in much higher concentrations than are obtained by percolation.
} 


\subsection{Accelerator Parameters}

As mentioned earlier, star densities for each accelerator are calculated using the Monte-Carlo hadronic cascade simulation programs. Table 2 summarizes the parameters used for each machine. The annual beam intensities in these calutulions assume $5 \times 10^{10}$ protons per bunch, high-intensity test beam operation and an operational year of $210^{7}$ seconds. These parameters are used to calculate the allowable proton loss for each accelerator needed to maintain a concentration of tritium in the groundwater below the $20 \mathrm{pCi} / \mathrm{ml}$ limit one meter from the outer edge of the accelerator enclosure.

Table 2. Parameters Used in Star Density Calculations.

\begin{tabular}{|c|c|l|l|}
\hline \multicolumn{2}{|c|}{ Accelerator / Beam Energy } & Material & Beam Intensity \\
\hline LInac & $1 \mathrm{GeV}$ & FIII & $3 \times 10^{20} \mathrm{p} / \mathrm{yr}$ \\
\hline LEB & $11 \mathrm{GeV}$ & FIII & $3 \times 10^{20} \mathrm{p} / \mathrm{yr}$ \\
\hline MEB & $200 \mathrm{GeV}$ & FIII/Chalk & $3 \times 10^{20} \mathrm{p} / \mathrm{yr}$ \\
\hline HEB & $2 \mathrm{TeV}$ & Chalk & $1.5 \times 10^{19} \mathrm{p} / \mathrm{yr}$ \\
\hline SSC & $20 \mathrm{TeV}$ & Chalk & $2 \times 10^{17} \mathrm{p} / \mathrm{yr} / \mathrm{ring}$ \\
\hline
\end{tabular}

\subsection{ESTIMATE OF CONSERVATISM}

The assumptions used in the groundwater model were chosen to render conservative predictions. This approach is used to provide a margin of error to compensate for unknown factors. This section reviews some of these assumptions and estimates their impact.

The largest degree of conservatism results from the use of saturation activities for the radionuclides. Activities will reach saturation only after prolonged continuous operations. For example, after 10 years of continuous operations, tritium concentrations will reach one fifth of the saturation value. Typical operations however, are not continuous over that time frame. The actual activity level will be some combination of build-up and decay based of operating history and will be significantly less than saturation for tritium.

The beam intensities used to calculate the beam losses represent a very ambitious test beam program. Initially, the accelerators will not be able to provide such intense beams. By the time these higher intensity beams are produced, the characteristics should be well known for these accelerators, and it should not be difficult to limit typical beam losses. There will be places along the accelerators where beam will be lost, such as injection and extraction points, and these areas can be predicted, and appropriate shielding placed in these areas to protect the groundwater.

Qualitatively, arguments can be made to determine the effect of groundwater movement. If the groundwater is slow moving it will reside in the activation zone for a long period of time and will approach saturation. Once it exits the activation zone this water will travel slowly, (allowing for decay) before it leaves the site boundary. If the groundwater is fast moving, it will not remain in the activation zone for any appreciable time and will only be a fraction of its saturation value. If the water movement starts out slow then speeds up, the increased movement would have to be accompanied by an increase in water volume, effectively diluting the water carrying the radionuclides. Therefore, all possible scenarios of groundwater movement will decrease the estimated activity either from low activation, decay or dilution. (The terms slow and fast refer to the amount of transport time relative to the decay constant for a particular radionuclide) 


\subsection{CONCLUSION}

This technical note describes a scheme to meet drinking water requirements in community wells by limiting the leachable activation one meter from the accelerator enclosure. It is shown that the concentration at one meter represents the average concentration for an activation zone extending four meters from the enclosure and containing more then $99.9 \%$ of the activity. This scheme does allow concentrations near the enclosure surface to exceed the drinking water standards by as much as a factor of ten. However, the higher concentration is mitigated by averaging the effect of any flow of the water. The model used to develop this scheme considers the activation to be at saturation. This will not occur until after years of operation. During this operation, the groundwater will be monitored and potential problem areas can be controlled through additional shielding of modified operations. The advantage of this model over the previous one is that it accounts for the site specific hydrology and both point and distributed losses.

ALARA (As Low As Reasonably Achievable) considerations for the design of new facilities call for a design which meets a more stringent criterion, namely $20 \%$ of the drinking water limit. Since transport and decay during transport to off-site wells is not considered in the model, this decay should serve to satisfy the ALARA requirement. In most cases this decay will provide far more than a reduction to $20 \%$ of the limit. ${ }^{7}$ 


\section{REFERENCES}

1. J.D. Jackson, "SSC Environmental Radiation Shielding," SSC-SR-1026, July 1987.

2. J.R. Sanford and D.M. Matthews, "SSCL Site-Specific Conceptual Design," SSCL-SR-1056, July 1990.

3. S.I. Baker, J.S. Bull and D. Goss, "Leaching of Ellis County (Texas) Rocks," Health Physics Society $38^{\text {th }}$ Annual Meeting, July 1993.

4. S.I. Baker, J.S. Bull and G.B. Stapleton, "Groundwater Activation Calculations at the SSC," Health Physics Society 38 ${ }^{\text {th }}$ Annual Meeting, July 1993.

5. S.I. Baker, "Groundwater Activation Summary," SSCL internal memo, April 7, 1992.

6. S.I. Baker, "Leaching of Accelerator-Produced Radionuclides," Draft, SSCL internal memo \#D10-000030.

7. D. Goss, "Transport parameters for worst-case flow within the near-surface aquifer in the region of the Linac/LEB/MEB," SSCL internal memo \#D10-000019, July 24, 1993. 

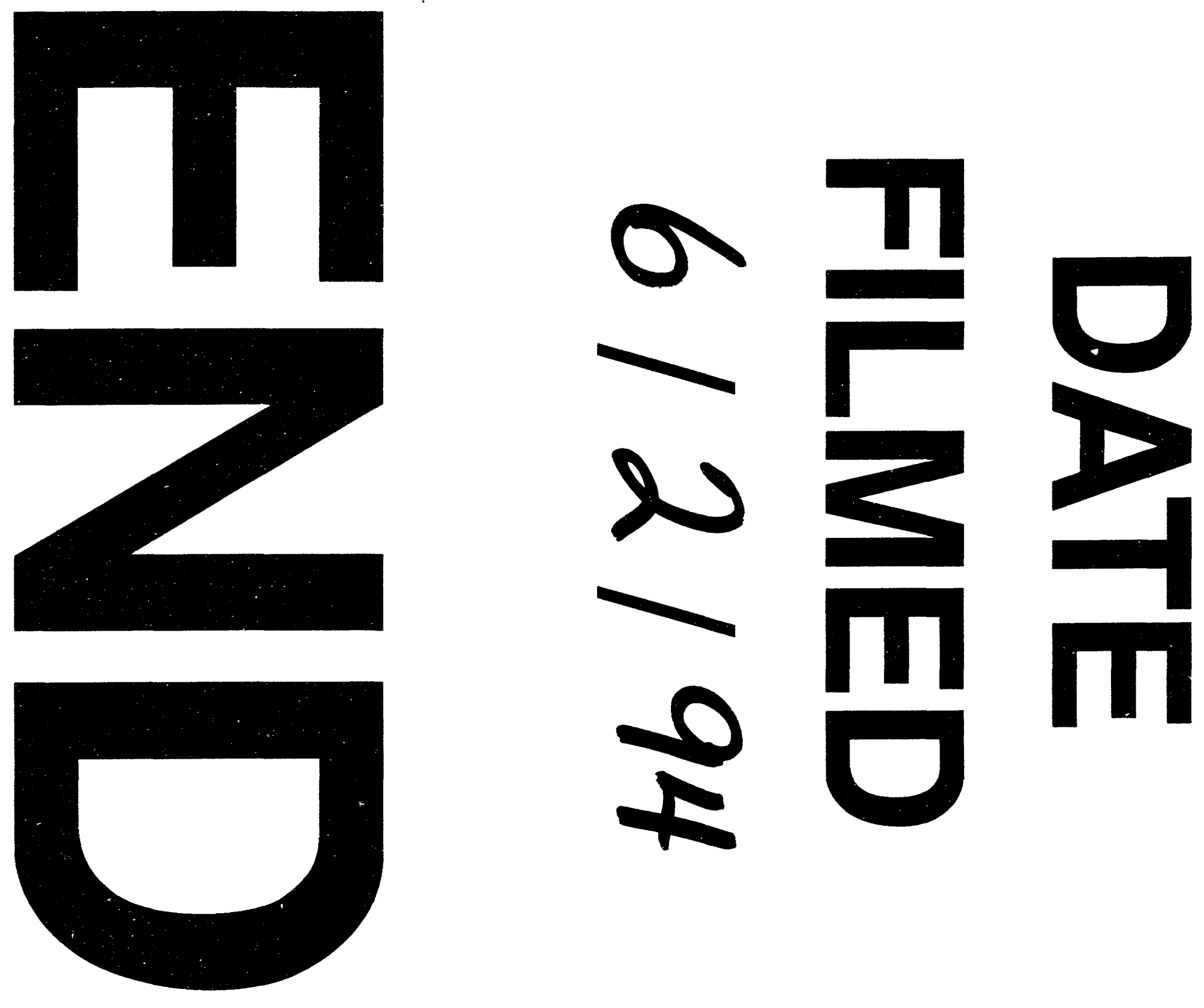
